\title{
Dawn of Organic Single Crystal Electronics-Hall Effect in Doped Organic Single Crystals
}

\author{
Masahiro Hiramoto* \\ Department of Materials Molecular Science, Institute for Molecular Science, Japan
}

Submission: February 03, 2018; Published: March 19, 2018

"Corresponding author: Masahiro Hiramoto, Institute for Molecular Science, 5-1 Higashiyama, Myodaiji, Okazaki, Aichi, 444-8787, Japan, Email: hiramoto@ims.ac.jp

\section{Mini Review}

Control of p-type and n-type that holes and electrons are responsible for electric conduction, respectively, by the addition of a trace amount of impurity (doping) is the central technology in 20 century's inorganic single crystal electronics as represented by the silicon chips, the solar cells, and the light emitting diodes. The number of carriers created by doping and their moving speed (mobility) can be freely evaluated by Hall Effect measurement using a magnetic field. However, in the field of organic electronics emerging in 21 century, no one has attempted not only to dope impurities into the organic single crystal itself but also the Hall effect measurement.

We combined the growth technique of rubrene organic single crystals which show the band-conduction [1,2] with the research group's original ultra-slow deposition technique of one billionth of a nano meter $\left(10^{-9} \mathrm{~nm}\right)$ per second, which includes a rotating shutter having aperture of the ratio reaching 1:1000 (Figure 1) $[3,4]$ and have succeeded in producing the $1 \mathrm{ppm}$ doped organic single crystal and in detecting the Hall effect signal [5]. It was found that the doping efficiency of organic single crystal is $24 \%$, which is close to that of silicon single crystal.

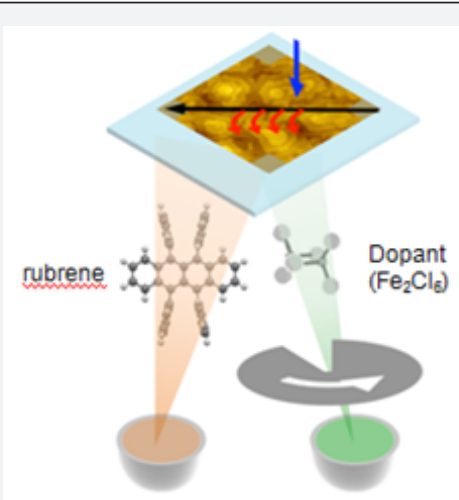

Figure 1: An ultra-slow co-deposition technique of one billionth of a nanometer $\left(10^{-9} \mathrm{~nm}\right)$ per second, which includes a rotating shutter having an aperture. An AFM image in the area of $5 \mu \mathrm{m}$ $x 5 \mu \mathrm{m}$ for acceptor $\left(\mathrm{Fe}_{2} \mathrm{Cl}_{6}\right)$-doped rubrene single crystal with magnetic field (blue arrow) and excitation current (black arrow) for Hall effect measurements is also shown.
In Figure 1, an AFM image of a $100 \mathrm{ppm} \mathrm{Fe}_{2} \mathrm{Cl}_{6}$ bulk-doped rubrene film on a rubrene single crystal substrate is shown. The slow deposition rate of $10-3 \mathrm{nms}^{-1}$ created homo epitaxial rubrene, i.e., the morphology of the deposited film showed many hexagonal structures which were oriented in the same direction and had the identical shapes to those of (001) rubrene single crystals with angles of $116^{\circ}$ and $127^{\circ}$. Obviously, the dopant molecules were present in the lattice of homo epitaxially grown rubrene single crystal film.

Hall voltage signals (Figure 2) were detected when applying a magnetic field to the $\mathrm{Fe}_{2} \mathrm{Cl}_{6}$-bulk-doped homo epitaxial layer. The sine waves of the AC magnetic field (blue curves) and the voltage signals (red curves) were clearly synchronized. Relationship between the current direction, the magnetic field, and the polarity of Hall voltage clearly indicates that the created carriers are holes which are in accordance of the fact that $\mathrm{Fe}_{2} \mathrm{Cl}_{6}$ is an acceptor dopant. A systematic decrease of Hall voltage with increasing the doping concentration means that the concentration of created holes increased.

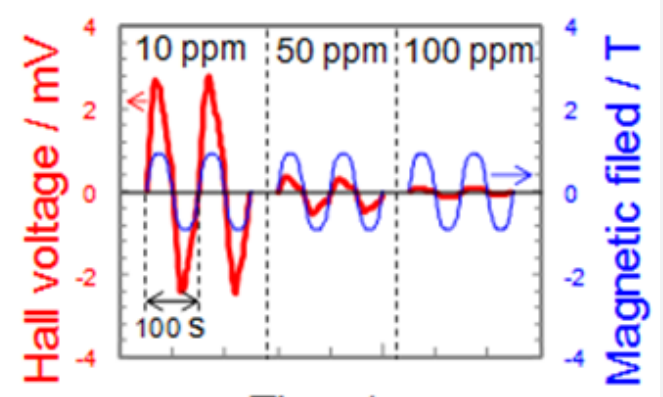

Time / s

Figure 2: Hall voltage signals (red) observed under the application of AC magnetic field (blue) for the 10-, 50-, and 100ppm doped devices.

The hole concentration $(\mathrm{N})$ and the Hall mobility $\left(\mu_{\mathrm{H}}\right)$ in a bulk-doped organic single crystal measured by the Hall effect are shown in Figure 3a \& 3c. The effects of doping on $\mathrm{N}$ and $\mu_{\mathrm{H}}$ for organic single crystals with inherent band-like features have 
not been previously observed. A surprising feature is the high ionization rate reaching $24 \%$ at $100 \mathrm{ppm}$ (Figure $3(\mathrm{~b})$ ), which corresponds to the ratio of the number of created holes to the number of acceptor dopant molecules $\left(\mathrm{Fe}_{2} \mathrm{Cl}_{6}\right)$. The ionization rate of $24 \%$ corresponds to the activation energy for acceptor dopant of $72 \mathrm{meV}$ and the Bohr's radius of $2.8 \mathrm{~nm}$ (Figure 4). This situation is quite resemble to the acceptor dopant (B) in $\mathrm{Si}$ having the activation energy of $45 \mathrm{mV}$ [6]. We presume that since the rubrene single crystal has the nature of band-conduction, a hole is not localized on a rubrene molecule and delocalized over the crystal lattice of rubrene molecules (Figure 4). This is a good news to create the new types of organic electronic devices utilizing many kinds of junctions made by doping, such as pn, pin-, and pnp-homo junctions, etc. in the bulk of organic single crystals.

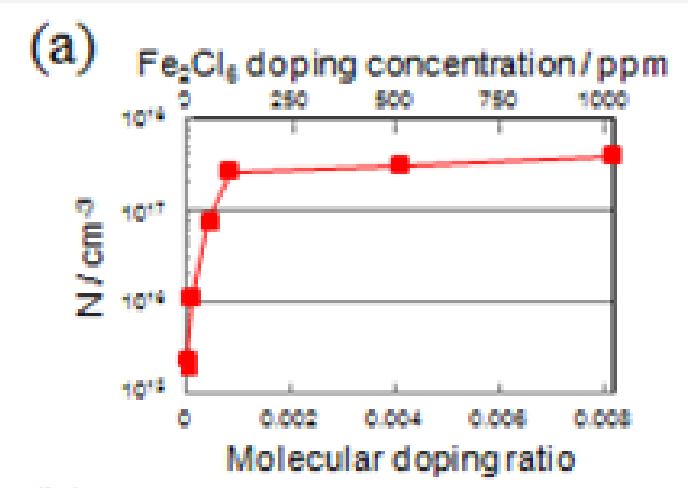

(b)

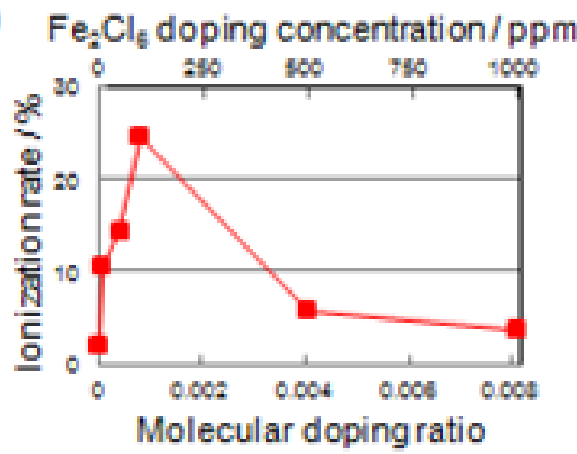

(c)

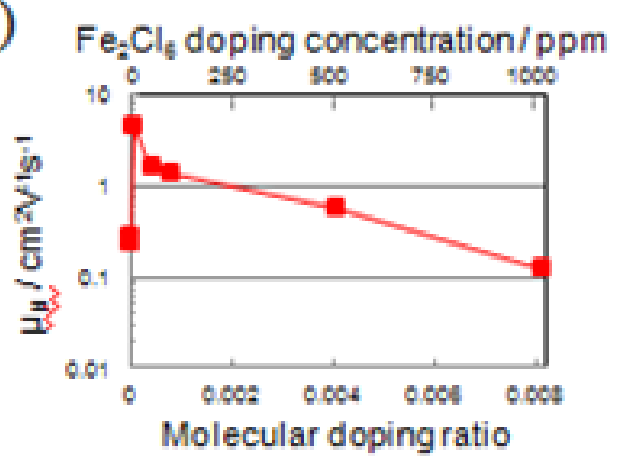

Figure 3: Dependences of (a) the hole concentration,

(b) the ionization rate, and

(c) the Hall mobility $\left(\mu_{H}\right)$ on the molecular doping ratio (MR) and the $\mathrm{Fe}_{2} \mathrm{Cl}_{6}$ doping concentration by volume for bulk-doped rubrene single crystals.

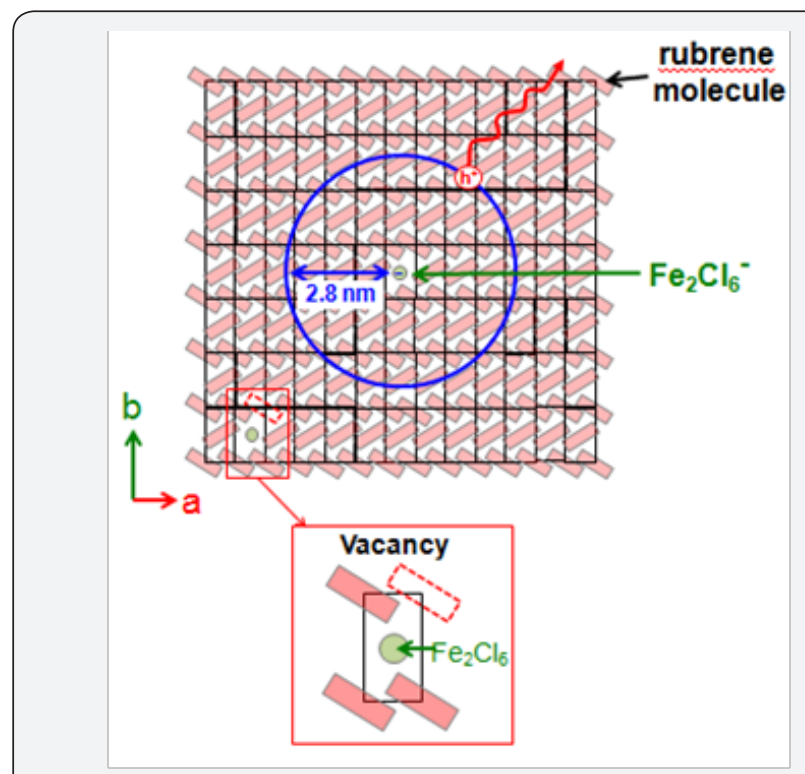

Figure 4: A hole weakly bound around the negatively ionized acceptor ion $\left(\mathrm{Fe}_{2} \mathrm{Cl}_{6}-\right)$. The activation energy and the Bohr's radius for bound hole corresponding to the ionization rate of $24 \%$ are $72 \mathrm{mV}$ and $2.8 \mathrm{~nm}$, respectively. Size of rubrene molecules is in real scale. The doping-induced defect caused by molecular vacancy is also shown.

The Hall mobility $\left(\mu_{\mathrm{H}}\right)$ decreased above $10 \mathrm{ppm}$. The gradual decrease in $\mu_{\mathrm{H}}$ can be attributed to the hole scattering by the ionized and neutral dopant molecules. Decrease of the ionization rate above $100 \mathrm{ppm}$ can be attributed to the doping-induced defects such as vacancies, interstitials, etc., which act as the hole traps (Figure 4). This result strongly suggests that there is a vast uncultivated field on the defects of organic single crystal similar to the inorganic single crystals like silicon.

The present results have the meaning of dawn of organic single crystal electronics similar to the silicon single crystal electronics. In future, organic single crystal devices such as high performance organic single crystal solar cells would be developed.

\section{References}

1. Takeya J, Kato J, Hara K, Yamagishi M, Hirahara R, et al. (2007) InCrystal and Surface Charge Transport of Electric-Field-Induced Carriers in Organic Single-Crystal Semiconductors. Physical Review Letters 98(18).

2. Lee B, Chen Y, Fu D, Yi HT, Czelen K, et al. (2013) Trap healing and ultralow-noise Hall effect at the surface of organic semiconductors. Nature Materials 12: 1125-1129.

3. Hiramoto M, Kubo M, Shinmura Y, shiyama N, Kaji T, et al. (2014) 'Band gap Science for Organic Solar Cells'. Electronics 3(2): 351-380.

4. Ohashi C, Shinmura Y, Kubo M, Hiramoto M (2015) Effects Of doping at the ppm level in simple $n+p$-homojunction organic photovioltaic cells. Organic Electron 27: 151.

5. Ohashi C, Izawa S, Shinmura Y, Kikuchi M, Watase S, et al. (2017) 'Hall Effect in Bulk-Doped Organic Single Crystals'. Advance Materials 29(23).

6. Ibach H, Luth H (2009) A book, "Solid-State Physics - An Introduction to Principles of Materials Science ( $4^{\text {th }}$ edn)", Springer, USA. 
This work is licensed under Creative Commons Attribution 4.0 License DOI: 10.19080/ETOAJ.2018.01.555558
Your next submission with Juniper Publishers will reach you the below assets

- Quality Editorial service

- Swift Peer Review

- Reprints availability

- E-prints Service

- Manuscript Podcast for convenient understanding

- Global attainment for your research

- Manuscript accessibility in different formats

( Pdf, E-pub, Full Text, Audio)

- Unceasing customer service

Track the below URL for one-step submission https://juniperpublishers.com/online-submission.php 